\title{
Hallazgos tomográficos de engrosamiento pleural, correlación clínico patológica
}

\author{
Andres David Garcia Wilches, Adriana Morales Cárdenas, María Alejandra Izquierdo Orozco, \\ Humberto Zapata, Ana María Alvarado Juan Ricardo Lutz Peña, Jorge Alberto Carrillo
}

\section{INTRODUCCIÓN}

La enfermedad pleural es frecuente y diagnostico y el diagnostico de su etiología permite un tratamiento eficaz. El $40 \%$ de los pacientes con derrame pleural permanecen sin diagnostico a pesar del análisis del liquido pleural y requieren biopsia. La biopsia pleural percutánea es un procedimiento mínimamente invasivo y seguro, cuya técnica (con o sin guía por imágenes), depende de la disponibilidad y experiencia del sitio de referencia. El rendimiento diagnostico de las biopsias pleurales percutáneas sin guía imagenológica es inferior a las realizadas con guía por imágenes (Sensibilidad $50 \%$ vs $70-87 \%$ ), principalmente en pacientes con malignidad, teniendo en cuenta que la enfermedad pleural neoplásica no es uniforme y se localiza en zonas inferiores, región evitada en las biopsias sin guía. En la literatura disponible se considera que las características operacionales de la biopsia percutánea sin guía de imágenes, varia de acuerdo a la extensión del engrosamiento pleural (difuso vs focal) sin embargo no se dispone de estudios formales aue lo confirmen.

OBEJETIVO

Establecer los hallazgos en tomografía computarizada (TC), predictores de buen rendimiento diagnostico en biopsia pleural percutánea sin guía por imágenes Describir alteraciones pleurales asociadas a la naturaleza de la enfermedad.

\section{MATERIAL Y MEDOTOS}

Estudio retrospectivo en 36 pacientes del Hospital Mayor Mederi, del año 2015 al 2018, que requirieron biopsia percutánea (realizada sin guía de imágenes). Se construyo una base de datos con los hallazgos tomográficos, clínicos e histológicos de estos pacientes. Análisis de datos SPSS y Exel. Búsqueda en la literatura con los términos MeSH "percutaneus biopsy", "pleural" y "computed tomography"

\section{RESULTADOS}

- El 66.7\% de las biopsias presentaron rendimiento diagnostico. • En los pacientes con biopsias diagnosticas, el $76 \%$ tenían engrosamiento pleural difuso, el $16 \%$ no tenían engrosamiento y $8 \%$ cursaban con engrosamiento focal. $\bullet$ En el grupo de los pacientes con biopsias no diagnosticas, el $41.6 \%$ tenían engrosamiento difuso y el $54.3 \%$ no tenían engrosamiento en la TC. $\bullet$ El $75 \%$ de las biopsias diagnosticas reporte malignidad. En este grupo, el $72.2 \%$ de los pacientes presentaron engrosamiento nodular de la pleura. $\bullet$ Los pacientes con engrosamiento pleural difuso en la TC de tórax, tenían significativamente mayor rendimiento diagnostico en la biopsia pleural percutánea, en comparación con el grupo sin engrosamiento o con engrosamiento focal (OR de 5,32 (p: 0,024)). • El 80\% de los pacientes con tuberculosis pleural tenían engrosamiento liso.

\section{CONCLUSIONES}

- El grupo de pacientes con enfermedad pleural neoplásica tenia con mayor frecuencia engrosamiento nodular de la pleura, mientras que en el de pacientes con tuberculosis, el $80 \%$ tenían engrosamiento liso, en concordancia con lo reportado en la literatura. $\bullet$ Teniendo en cuenta estos hallazgos, podemos concluir que el engrosamiento pleural nodular sugiere enfermedad neoplásica (primaria o secundaria), principalmente enfermedad metastásica y mesotelioma. Eventualmente entidades infecciosas pueden presentar este hallazgo, como la tuberculosis. Adjuntos:Tabla-biopsias.png

principalmente enfermedad metastásica y mesotelioma. Eventualmente entidades infecciosas pueden presentar este hallazgo, como la tuberculosis:

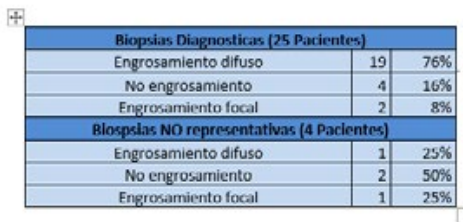

